\title{
'DO YOU SEE WHAT I'M DEALING WITH HERE?' VICIOUS CIRCLES IN CONFLICT
}

\section{Charlie Irvine}

\begin{abstract}
We know that our thinking is affected by conflict; this applies to groups and nations as much as to individuals. Mediators are at the sharp end of this phenomenon, and those we work with often find each other's behaviour at best inexplicable and at worst malicious. This article considers how biases and heuristics (mental shortcuts) can exacerbate disputes. Two cognitive biases in particular can contribute to the growth of conflict: the fundamental attribution error and the self-serving bias. Using a workplace mediation case study, the article traces the step-by-step mechanics of conflict in people's thinking and its tendency to set in motion vicious circles of suspicion and defence. It goes on to provide a critique of bullying and harassment policies before proposing that they begin with a mediation stage in order to combat attribution errors by bringing more data into play.
\end{abstract}

\section{Keywords}

Conflict, vicious circles, cognitive errors

\section{Introduction}

"No man can think clearly when his fists are clenched" (George Jean Nathan).

Conflict is a puzzle. Friedrich Glasl's vivid language captures its steady descent from "hardening” all the way to "together into the abyss" (Glasl, 2000). We all know about its destructive power: many millions died in the great wars of the $20^{\text {th }}$ century, and yet it can be tempting to conceive of others in conflict as silly. Why do people make such self-destructive choices? Think of the couple recently referred to mediation in Ireland who had apparently appeared in court over seventy times (Walsh, 2013). Each individual step must have seemed logical to the participants, yet the overall result defies rationality.

All of this highlights the crucial importance of perception. Our actions rely on fine judgements about the actions and intentions of others: a great deal is at stake. Too trusting, and we risk failing to defend ourselves against a malign foe. Not trusting enough, and we have no allies and even turn friends into foes. Starting with a case study from the world of workplace conflict, I describe some of the biases that affect our perception and their implications for conflict resolution. 


\section{Margaret and Colin}

Margaret and Colin are senior professionals in a busy healthcare organisation. They are both in their mid-40's. Colin was appointed to the management team 18 months ago, meaning that Margaret and five others now report directly to him.

Margaret and Colin work on separate sites. Before Colin was appointed to the Management Team they got on reasonably well as colleagues, occasionally visiting each other's sites but having little day-to-day contact. After Colin's appointment, things deteriorated sharply. Margaret has accused Colin of bullying her. She initially complained to the General Manager and, when he took no action, became ill with stress. She also raised a formal grievance against Colin, citing bullying and harassment. By the time this matter came to mediation Margaret had been off sick for a year. The terms of her contract mean that she continued to receive her substantial salary for the first twelve months of absence, and will receive $50 \%$ for the following twelve months. In the meantime, the organisation has had to employ a temporary person to cover Margaret's work at a cost of approximately $£ 150,000$ per annum (more than her salary).

Margaret says that Colin's bullying is particularly severe, and she has turned to the Employers' Guidance on Bullying and Harassment (NHS, 2006) to help her categorise the behaviour. She cites the following as examples:

Bullying by aggressive and intimidating behaviour - angry, aggressive tone, viciously spitting out words, scarlet face, raised voice, almost 'losing it'

Bullying by intimidation/isolation - scheduling staff interviews for the only day when Margaret would not be accompanied by a colleague; showing anger when Margaret refused to agree to a change of plan during the interview

Bullying by abuse of power/ignoring - when Margaret asked for help with a rota, shrugging his shoulders and saying 'someone has to do it'

Harassment - calling Margaret and colleague 'you girls'

Bullying by abuse of power/exclusion - discussing a plan for a change in service delivery that would have a significant impact on Margaret without consulting her

Bullying by setting unrealistic targets that are unreasonable - a public statement, the consequences of which could only mean more work for Margaret

Bullying by deliberate withholding of information - not providing an agenda for a forthcoming meeting

Bullying by bumiliation/undermining/unfair criticism - disbelieving her account of a complaint by another healthcare professional that she had kept him waiting for two hours

This helpful list allows Margaret to describe eight pages' worth of humiliation, belittlement and daily anguish. It is little surprise, then, that her performance and health have suffered.

Having heard such a catalogue of accusations, we are no doubt curious to learn whether they were upheld (telling us that Colin is an angry, toxic, bully), or not (telling us that Margaret is delusional, manipulative or both). Being a typical mediator, however, I will explain why neither is true. Drawing on simple, well supported ideas from the field of social cognition, I suggest that this case, and many others like it, illustrate 
three phenomena:

1) The vulnerability of Western people to errors of attribution and cognition

2) The part these errors play in the growth of conflict, creating 'vicious circles'

3) That bullying and harassment policies can exacerbate the very problems they exist to tackle, acting as a form of self-fulfilling prophecy.

\section{Cognitive Errors}

We all need to make daily judgements about the people around us. Are they being friendly or bitchy, honest or deceitful, trustworthy or sly, generous or self-aggrandising? Social psychologists call these judgements “attributions" (Heider, 1956) and we are generally pretty good at making them: hardly surprising when our survival could depend on their accuracy. If a stranger approach me on a dark night, I probably use all my powers of observation and experience to work out whether to cross the street or stride on confidently.

However, many social situations are ambiguous. If a colleague makes a funny remark about my appearance, is she affectionately teasing or subtly undermining? If I am late with a piece of work, does my boss see me juggling equally important priorities, or just the missed deadline? If she gives me extra work, is it compliment or punishment? The answers to these questions can depend less on the evidence than on our thinking: "We do not see the world as it is. We see the world as we are" (Anais Nin).

To understand attribution theory and its explanation for errors in our thinking, we first need to distinguish between 'internal' and 'external attributions. Suppose a senior colleague is tapping on his iPhone while I am speaking in a meeting. I can't see inside his head, but I need to explain this potentially undermining behaviour, particularly if my social status is at stake (Fesenmaier, 2012). I might guess that he is self-important: his affairs matter more than the rest of us. This would be an internal attribution. I account for his behaviour by factors internal to him: it's the way he is. Internal (or dispositional) attributions are stable and predictable and thus help us to plan. I will be wary of this guy in future.

On the other hand, (particularly if he has a reputation as a warm, decent person) I might guess that he is dealing with some particularly worrying concern. He may just have discovered, for example, that his child is ill and needs to be collected from school. This would be an external attribution. I attribute his behaviour to this fleeting circumstance, meaning that I should attach little importance to it in my long-term judgement of him. External (or situational) attributions are unstable: they don't help me predict how he will behave in future, different, situations.

Making internal and external attributions is daily fare and we get it right most of the time. However, one bias in our judgement is so frequent that it has been dubbed the "fundamental attribution error" (Pennington, 2000:38- 43). It describes the tendency, when explaining the behaviour of others, to overestimate the role of internal factors and underestimate the part that external factors play; "to assume that an actor's behavior and mental state correspond to a degree that is logically unwarranted by the situation" (Andrews, 2001:11). Put simply, we habitually make internal attributions when we ought to be making external 
attributions.

Psychologists have posited three possible explanations for the phenomenon:

1) The other person's behaviour "engulfs our perceptual field" (Heider, cited in Pennington, 2000:40). When we observe someone in a scene, it is natural to see the person first rather than their situation. It requires further attention to notice the surrounding circumstances.

2) We construct the world in two stages, spontaneously then deliberatively. Our first impression can be corrected by further attention, given time.

3) Cognitive load. It seems that we are more prone to the fundamental attribution error when we are "cognitively busy" (Pennington, 2000:41; Tierney, 2011). People who were distracted by other tasks were less likely to correct dispositional attributions, even when situational information was readily available.

In summary, when we are under stress or simply not paying full attention, we are more prone to the fundamental attribution error. Going back to my inattentive colleague, "he's a bad guy" rather than "he's having a bad day".

But that's not the whole story. What about ourselves? People have marked tendency to view their own behaviour differently, in what are known as "actor-observer differences" (Pennington, 2000:43-45; Parkinson, 2008:59). In general, we are more likely to make external, or situational, attributions about our own behaviour, while preferring internal, dispositional, attributions for the behaviour of others. So if I am the one stealing a glance at my phone while someone else speaks, I will explain this poor behaviour with reference to the looming family crisis, or the person who desperately needs to get hold of me. I am less likely to conclude that I am rude or arrogant (if I notice my own disposition I am likely to describe it charitably as an inability to multitask!)

A related phenomenon depends on the consequences of our actions. When things have gone well we are likely to attribute our success to internal or dispositional factors: "I did well in that exam because I worked hard and have an aptitude for the subject." Conversely, poor outcomes garner external, situational attributions: "The teacher is a notoriously tough marker and I have a heavy workload this semester." This is known as the "self-serving bias": "the tendency to take credit for success and deny responsibility for failure" (Fiske \& Taylor, cited in Pennington, 2000:49; Parkinson, 2008:61). It also has a mirror image, the "accuser bias": "We readily bring to mind factors within the person's control that might explain his or her behaviour, and tend to ignore or dismiss factors beyond his or her control that might explain the behaviour" (Allred, 2005:85).

The self-serving bias seems to go further, leading us to conclusions that favour our perspective even when the facts are ambiguous. One notable experiment involved legal students and practitioners being asked to predict a likely damages award based on identical facts (a motorcyclist colliding with a car and suing the driver for $\$ 100,000$ ) (Babcock and Lowenstein, 1997). Unsurprisingly the range of predictions was large, but participants had been randomly assigned to two conditions: in one they acted for the plaintiff, the other for the defendant. Over a number of experiments, plaintiffs' attorneys estimated a figure $\$ 14,000$ to $\$ 21,000$ dollars higher than that of defendant lawyers.

The tendency to make dispositional attributions, including the fundamental attribution error, is less 
pervasive in parts of Asia. Indian and Chinese people appear more likely to consider the situation or circumstances when apportioning responsibility for a harmful act. More individualist cultures like the UK and USA seem to favour dispositional explanations, perhaps because they chime with an emphasis on personal responsibility (Parkinson, 2008:58).

This picture is further enriched by a glance at the neuroscience of conflict. Once aroused by threat or anger we are programmed to behave in ways that minimise the chances of rational, reflective thought and maximise instinctual, reflexive actions. The limbic system with its repertoire of emotions protects us from immediate danger and increases our chances of survival in part by acting before the neocortex and other 'higher' parts of the brain kick in (Lack and Bogacz, 2011). But in complex, nuanced environments like the contemporary workplace we can find ourselves charging down a road of instinctive fight and flight responses quite inappropriate for the problems we need to solve.

\section{The growth of conflict}

So how might these patterns of thinking affect Margaret and Colin? Let's take her first heading, “Bullying by Aggressive and Intimidating Behaviour.” At first sight, this is inexcusable. If Colin adopts an angry, aggressive tone and spits out his words, almost losing his temper, he must be an aggressive, angry person. Well, possibly. An outside observer may be able to offer alternative explanations: perhaps he is having a bad day; perhaps he is under pressure from those above him; perhaps he sees Margaret as thwarting his goals. But Margaret is not an outside observer: she is the one being harmed by Colin's outburst. He "engulfs her perceptual field." She feels threatened; she sees him; and the causal link is made. He is a bully. Crucially, she is unlikely to pay much attention to herself and any contribution she may have made to the situation.

Furthermore, all this happens very quickly. Primal emotions like fear cause us to react in fractions of a second. So Margaret is likely to be making her attributions spontaneously rather than deliberatively, giving her less time to correct any errors. And she is undoubtedly under stress, rendering her "cognitively busy" and therefore less likely to look for external explanations for Colin's behaviour. Add to this the likelihood that this was not the first difficult encounter between the two: Margaret's memories of previous negative attributions about Colin (he is aggressive, threatening, nasty) almost certainly lead her to attribute his actions to his disposition rather than the situation.

The actor-observer difference may also come into play. Colin shouted at her (external): all she could do was defend herself. In her view Colin's behaviour, on the other hand, stems from his aggressive and unreasonable nature (internal). Colin, however, might have brought his own dispositional attributions into the room, recalling that Margaret had a record of challenging management decisions.

There is every chance that the third related phenomenon, the "self-serving bias" is also at work. Margaret's situational account of her own actions renders them reasonable or even unavoidable. On the other hand, the "accuser bias" means that Margaret will be conscious of how much control Colin should have over the situation and will probably dismiss "factors beyond his control", i.e. her own approach. Therefore, no excuse can be made and he should be condemned for his behaviour. 
This takes us to the heart of the vicious circles that pervade workplace conflict. In the social world, anyone we observe is also observing us. If we bring our own fears, hostility or anxiety to an encounter, it is unlikely that the other person will miss it. As Lax and Sebenius (2006:81) put it "Ifyou're seated at the negotiating table in the absolute, unshakable conviction that your counterpart is a stubborn and difficult character, you are likely to act in ways that will trigger and worsen those very behaviours." In a kind of self-fulfilling way, if I expect trouble I may well get it. I take defensive action: you see me as aggressive. I take avoiding action: I'm rude. I seek support from others: I'm plotting against you. What emerges forcefully is this: at the very times when we most need to be discerning about others, we are least likely to be. We do not accurately interpret motives from actions.

\section{Why Bullying and Harassment Policies Make Things Worse}

One important clarification: I am not saying that bullying is always a matter of perception. People can be unkind, disrespectful, even contemptuous, and act in ways that harm and humiliate others. A great deal of behaviour is, however, ambiguous and, as we have seen, human judgement is fallible and prone to bias. The most significant step in resolving many situations is to enrich that judgement, taking account of unseen situational factors affecting the other person and incorporating unacknowledged internal factors in our view of ourselves. This requires conversation. It is slow, painstaking work.

Bullying and harassment processes do the opposite. In a well-intentioned effort to protect the vulnerable they freeze everyone's perspectives at their lowest ebb. Taking the accuser's story as a 'true' starting point, the accused is immediately labelled a bully, required to defend her or himself and sometimes even marched off the premises. The accuser gets no explanation, no insight into the sources or causes of conflict, nor of the situational factors (including her own actions) affecting the behaviour and her perception of it. And once behaviour is framed by the accusatorial process, any attempt to explain will be seen as an excuse, a convenient, retrospective way to wriggle out of responsibility.

Margaret's case also illustrates the power of labels. Bullying and harassment policies invite the accuser to rehearse their victimhood, via terms like isolation, exclusion, intimidation, and abuse of power. All of these reinforce attribution errors, reducing to zero any external explanatory factors and leaving open only two equally unpalatable internal explanations: bad or mad. And once we are dealing with a malign or crazy foe we can no longer treat that individual like a fellow human being; our only options are to drive the threat away or flee ourselves.

Reality is messier. A bullying allegation is investigated. The behaviour complained of is ambiguous, the evidence inconclusive or the explanation plausible. The complaint is not upheld. The victim then refuses to return to work. Nothing in the process has enriched her or his understanding of the other person's perspective; equally the accused has learned little or nothing of the accuser's perspective, probably regarding the allegations as 'lies'. The process produces neither change nor the incentive to change. 


\section{Conclusion: What's the Tonic?}

At the risk of falling victim to Mandy Rice-Davies's wise quip - "Well he would, wouldn't he?" - I will suggest that consensual processes like mediation ought to be attempted first before formal, adversarial investigation. This is not because they are nice! Mediation is far from nice, and those who are asked to consider it often display considerable anxiety at the thought of dialogue with the 'adversary'.

It is rather because these processes allow more data to emerge. By removing the need to maintain a legally watertight position, a reasonably competent mediator can help people to enrich their understanding, adding situational and dispositional factors to each side's perspective. And if I begin to understand how my behaviour affects you, not only can I explain it, I can in the right circumstances apologise for it and explain how I will modify it in future. This does not mean that bullying is not being taken seriously. On the contrary, the mediator honours each person's account of the situation. One mediation quality that is frequently overlooked is its capacity to help us hear our own thoughts more clearly.

To return to Margaret and Colin, their path was not particularly straightforward. It took four meetings over a couple of months to allow Margaret to work things through with Colin and contemplate a return to work.

However, what is striking is that, before she did, she and Colin wrote a joint letter to senior management setting out some shared concerns and explaining that they were now able to work together. Colin had gone from being 'enemy' to 'ally.'

I finish with a striking example. Another client spoke of being physically sick on the way to work each day because of her colleagues' concerted campaign of bullying. Their bullying behaviour included talking and laughing when she walked into the room before falling silent. She dreaded each day at work and was on the brink of leaving. Following a difficult and painstaking mediation, which included a great deal of soul-searching on both sides, we held a review session some months later. Describing how things had changed she said this: "Before when I heard them laughing I assumed they were laughing at me. Now I tell myself that they're just laughing."

What had happened? In the mediation she had laid out exactly how the behaviour affected her. Thus the story was enriched for both parties, with the accused 'ringleader' learning how their actions caused distress, but with the accuser also learning about possible situational or innocent explanations for those actions. Over the ensuing weeks, the resultant change in atmosphere had reduced her anxiety levels, and thus her cognitive load, giving her time to re-evaluate her spontaneous judgements about the causes of the team's actions. This led her to feel more confident and to believe that she was a respected member of the team. And so the vicious circle of bullying and isolation had been reversed, with cooperation and trust gradually rebuilding with each positive step. To reiterate, while investigation and punishment remain important tools for egregious and discriminatory bullying, employers would do well do begin with a step that includes dialogue and brings neglected data into play. 


\section{References}

Allred, K. (2005) Relationship Dynamics in Disputes: Replacing Contention with Cooperation. in Moffitt, M. and R. Bordone (eds) The Handbook of Dispute Resolution. San Francisco: Jossey-Bass.

Andrews, P. (2001) The psychology of social chess and the evolution of attribution mechanisms: explaining the fundamental attribution error. Evolution and Human Behavior. 22:11-29

Babcock, L. and G. Loewenstein, (1997) Explaining bargaining impasse: The role of self-serving biases. Journal of Economic Perspectives. 11 (1): 109-126

Fesenmaier, K. (2012) Neuroscientists Find that Status Within Groups Can Affect IQ [Online] Available from http://www.caltech.edu/content/neuroscientists-find-status-within-groups-can-affect-iq [Accessed $13 / 11 / 13]$

Fiske, S, and S. Taylor (1991) Social Cognition (2nd Edition). New York: McGraw-Hill.

Glasl, F. Konfliktmanagement. Ein Handbuch für Führungskräfte, Beraterinnen und Berater. Cited in Jordan, T. (2000) Glasl's 9-stage Model of Conflict Escalation. [Online] Available from http://www.mediate.com/articles/jordan.cfm [Accessed 13/11/13]

Heider, F. (1958) The Psychology of Interpersonal Relations. New York: Wiley.

Jeremy Lack, J. and F. Bogacz (2011) The Neurophysiology of ADR and Process Design: A New Approach to Conflict Prevention and Resolution? [Online] Available from http://www.mediate.com/mediator/attachments/28823/J.\%20Lack\%20\&\%20F.\%20Bogacz\%20-$\% 20$ The $\% 20$ Neurophysiology $\% 20$ of $\% 20$ ADR $\% 20$ and $\% 20$ Process $\% 20$ Design $\% 20$ (Neuroawareness).pdf [Last accessed 14/11/13].

Lax, D and J. Sebenius (2006) 3D Negotiation: Powerful Tools to Change the Game in Your Most Important Deals. Boston: Harvard Business School Press.

NHS Employer's Guidance: Bullying and Harassment (2006) [Online] Available from http://www.nhsemployers.org/Aboutus/Publications/Pages/BullyingAndHarassment.aspx [Accessed 13/11/13]

Parkinson, B. (2008) Social Perception and Attribution in Hewston, M., W. Stroebe and K. Jonas (eds) Introduction to Social Psychology: A European Perspective (4th Edition). Oxford: Blackwell Publishing.

Pennington, D. (2000) Social Cognition. London: Routledge.

Tierney, J. (2011) Do You Suffer from Decision Fatigue? [Online] Available from http://www.nytimes.com/2011/08/21/magazine/do-you-suffer-from-decision-

fatigue.html?_r=1\&pagewanted=all\&goback=\%2Egmp_935617\%2Egde_935617_member_131502453 [Accessed 1/11/13]

Walsh, S. (2013) Mediation in Cases in (sic) Domestic Violence: Between a Rock and a Hard Place. [Online] Available from http://kluwermediationblog.com/2013/11/06/mediating-in-cases-in-domestic-violencebetween- a-rock-and-a-hard-place/ [Accessed 13/11/13] 
Charlie Irvine is Visiting Professor, University of Strathclyde School of Law. His academic work is concerned with the role of alternative dispute resolution within the justice system as well as conflict resolution and the arts. In 2010 he was lead author of a literature review for the Health Professions Council which has informed its policy on the use of mediation for complaints against health professionals. He is Visiting Professor at Strathclyde Law School and Adjunct Professor at John Marshall Law School (Chicago), for whom he has developed their annual International Summer School in Mediation. He is also an experienced mediator and trainer, and Chair of the Scottish Mediation Network. 